\title{
TÉCNICAS DE DISTINÇÃO NOS PRECEDENTES E RECURSOS REPETITIVOS: Democratização Processual e Tecnologias do Processo Civil Brasileiro
}

\section{Carlos Fernando de Barros Autran Gonçalves*}

Resumo: Este artigo trata das técnicas da distinção no direito processual civil brasileiro, em matéria de precedentes judiciais e de recursos repetitivos. Objetiva-se primeiro expor as diferentes técnicas da distinção para, em seguida, ajustá-las à interpretação processual no quadro contemporâneo da democratização e da dogmática tecnológica do processo civil. Utiliza-se o método qualitativo de abordagem dedutiva, a partir da legislação processual civil e da doutrina jurídica, com análises do direito comparado.

Palavras-chave: técnicas; distinção; precedentes; repetitivos; democratização.

\section{RULES OF DISTINGUISH ON BINDING PRECEDENTS AND SERIAL CASES LAW: Democratricy and Technology in Procedure Civil Brasilian Law}

\begin{abstract}
This paper approaches the rules of distinguish into procedural civil brazilian law, about binding precedents and serial cases law. First, the goal is study the differences on rules of distinguish and, second, the goal is fit the interpretation on contemporary frame of the democratization into procedure civil law and of the legal system technology. This paper use the qualitative and deductive method, reasoned by legal system and law doctrine, with comparative law lessons.
\end{abstract}

Key-words: rules; distinguish; precedents; serial cases law; democratization.

\section{INTRODUÇÃO}

Este artigo propõe analisar os dois conceitos jurídicos de "distinção", previstos no Código de Processo Civil. Um dos conceitos está disposto no art. 489, § $1^{\circ}$, VI, no que tange à necessidade de fundamentar a sentença civil na hipótese de distinção do precedente judicial alegado no caso concreto; e o outro conceito decorre do art. 1.037, § $9^{\circ}$, do mesmo diploma legal, no que diz respeito à hipótese de distinção de um caso concreto em relação à questão afetada nos recursos especial e extraordinário repetitivos. Em ambas as hipóteses legais, há o termo "distinção", com técnicas processuais que não se confundem. No contexto do direito anglo-americano, uma das técnicas está relacionada à teoria dos precedentes; e a outra, às ações coletivas.

\footnotetext{
${ }^{*}$ Graduado em Direito (UNIP/1997). Mestre em Teoria do Direito (UFPE/2010). Doutorando em Direito Processual (PUCRS). E-mail: autran.juris@gmail.com
}

Rev. de Processo, Jurisdição e Efetividade da Justiça | e-ISSN: 2525-9814 | Porto Alegre | v. 4 | n. 2 | p. $23-42$ | Jul/Dez. 2018 
A problemática que se pretende considerar nestas aludidas técnicas processuais de distinção é a seguinte: como a democratização do processo civil brasileiro pode condicionar a interpretação das técnicas processuais de distinção? A hipótese traçada nesta discussão é a de que, primeiro, por haver mais do que uma técnica de distinção no processo civil brasileiro, o termo "distinção" aplicado às diferentes técnicas não possui o mesmo efeito jurídico, o que exige, por consequência, o reconhecimento de funções e métodos de aplicação diferenciados, desde que tais funções e métodos atendam ao aperfeiçoamento democrático do processo civil.

No quadro dos fundamentos teóricos desta interpretação processual civil, cabem as lições de Gisele Mazzoni Welsch (2016), no ensaio sobre a legitimação democrática do poder judiciário; e de Tércio Sampaio Ferraz Jr. (1998) acerca da dogmática jurídica. No atinente às duas citadas técnicas de distinção, pode-se afirmar que estas já se servem da rede mundial de computadores, com base no art. 927, $\S 5^{\circ}$; e no art. 979, $\S 1^{\circ}$, ambos do Código de Processo Civil. Tais regras processuais preveem que a decisão judicial fixadora, respectivamente, do precedente e da questão afetada dos casos repetitivos seja comunicada na rede mundial de computadores. Esta comunicação na rede de informática possibilita a democratização do processo civil, por meio da transparência dos elementos identificadores da vinculação ao precedente e da afetação ao recurso repetitivo. Além disto, facilita o emprego de ambas as técnicas de distinção, tanto a técnica de distinção em relação ao precedente, como a técnica de distinção em relação à tese no recurso repetitivo. Assim, em vista desta transparência na rede mundial de computadores e da possibilidade de distinção, nota-se a presença de uma ideologia democrática da dogmática processual civil, de modo que o sistema processual civil seja uma ferramenta tecnológica a serviço do jurista para cumprir tal finalidade democratizante.

Em torno destas questões, objetiva-se associar à democratização do processo civil o uso adequado dos procedimentos técnicos que levam à efetividade do sistema processual civil. A finalidade específica deste estudo é a de ampliar o debate em torno das técnicas processuais de distinção, no espectro da teoria da decisão jurídica. Este artigo se justifica na interpretação adequada destas técnicas de distinção, para fins de efetivar o direito ao processo justo. A abordagem dedutiva prepondera neste estudo, a partir das inferências da lei e da literatura jurídica. Recorre-se, ainda, à análise comparativa e hermenêutica, com o suporte das técnicas estrangeiras da teoria dos precedentes.

\section{Lições sobre o Distinguishing da Teoria dos Precedentes}

Rev. de Processo, Jurisdição e Efetividade da Justiça | e-ISSN: 2525-9814 | Porto Alegre | v. 4 | n. 2 | p. $23-42$ | Jul/Dez. 2018 
Para seguir o precedente, a decisão jurídica é justificada na vinculação à ratio decidendi ou, como preferem denominar os norte-americanos (FACCHINI NETO e CORDEIRO, 2016), na vinculação ao holding. Na teoria dos precedentes, o termo holding equivale à expressão ratio decidendi; e o que não for ratio, corresponde ao "dito morto" do precedente; obter dicta ou obter dictum, que em nada vincula, embora possa servir como subsídio à persuasão racional (persuasive precedent).

É curioso perceber como tais expressões são hoje correntes na linguagem processual do direito brasileiro. Entretanto, tal terminologia provém da doutrina do stare decisis utilizada na tradição do common law, cujas técnicas são variadas. Desta forma, ao falar sobre a técnica do distinguish ou distinguishing, aonde o campo de estudo e aplicação prática já é vasto, não se quer tratar das técnicas da superação, sinalização e transformação, conforme traduzido no processo civil brasileiro (CRAMER, 2016), todas estas pertinentes à teoria dos precedentes.

Com respeito à técnica do distinguishing proveniente da teoria dos precedentes do common law, a primeira lição que a doutrina processual civil brasileira pôde assimilar é a de que, na feliz expressão de Marco Félix Jobim (2013), quanto à palavra inglesa distinguishing, não cabe a simples tradução para o termo "distinção". É necessário buscar uma compreensão mais apropriada desta técnica; sobretudo, quando o intérprete compara os institutos do direito anglo-americano com as técnicas do direito processual civil brasileiro.

Por outro lado, o termo "distinção" presente na legislação processual civil brasileira pode ser associado ao distinguishing do direito anglo-americano, na medida em que vem atender a mesma função normativa de fundamentar a inaplicabilidade do precedente, por conta dos elementos de diferenciação que o fato do caso concreto apresenta em relação aos motivos determinantes enunciados no precedente. Ainda que seja, então, relevante entender o distinguishing de maneira a não interpretar a técnica processual de distinção como um mero legal transplant do direito estrangeiro, também é necessário observar a utilidade da doutrina do stare decisis para fins de interpretação dos precedentes brasileiros.

$\mathrm{O}$ argumento da utilidade de se comparar institutos jurídicos estrangeiros, assim, afasta a clausura atribuída ao significado normativo de um texto legal ou de uma tradução do conceito. Deve-se questionar se é útil fazer a comparação, para fins de examinar a validade de se equiparar os institutos, como uma medida pragmática voltada à funcionalidade normativa 
inserida na ordem jurídica. Tal formulação teórica não deriva do legal transplant; ajusta-se antes à teoria funcional do direito comparado, aonde a busca pela semelhança entre as duas ordens jurídicas verifica, em primeiro plano, o que é resolvido pelo direito (HERZOG, 2014).

Nesta perspectiva funcional, pode-se referir ao distinguishing ou distinguish como sendo equivalente à técnica de distinção. Desta forma prática trata-a Didier Jr. (2015), quando observa duas acepções para o termo distinguish, conforme segue:

(i) para designar o método de comparação entre o caso concreto e o paradigma (distinguish-método) - como previsto no art. 489, § $1^{\circ}, \mathrm{V}$, e $927, \S 1^{\circ}$, CPC; (ii) e para designar o resultado desse confronto, nos casos em que se conclui haver entre eles alguma diferença (distinguish-resultado), a chamada "distinção", na forma em que consagrada no art. 489, $\S 1^{\circ}$, VI, e 927, $\S 1^{\circ}$, CPC (idem, p.491).

É possível estender a primeira acepção do distinguish também ao termo "distinção" previsto no art. $1.037, \S 9^{\circ}$, do Código de Processo Civil, no que tange à distinção sobre a questão de direito afetada nos recursos repetitivos. É fato que, nesta primeira acepção, as duas técnicas processuais de distinção podem ser associadas ao distinguishing. Acontece que a doutrina processual civil brasileira costuma ignorar a associação entre a técnica de distinção da teoria dos precedentes e a "distinção-método" do procedimento de casos repetitivos.

É possível que o distinguish adaptado do common law faça o direito brasileiro valorizar mais a segunda acepção do termo "distinção". Na tradição do direito codificado, conforme constatado, a lei regra o procedimento de distinção. Nesta qualidade, a técnica de distinção surge como critério de decisão judicial, à luz do art. 1.037, § $9^{\circ}$, balizando a decisão judicial de não-afetação de um caso concreto ao caso-paradigma do recurso repetitivo.

Em estudo comparativo com o direito anglo-americano, afigura-se mais este traço de originalidade do direito brasileiro quanto à existência de duas técnicas de distinção, desde que tais técnicas sejam tidas também na primeira acepção aludida por Didier Jr. (2015), servindo como técnica de decisão jurídica. Na outra acepção, prevista no art. 489, § $1^{\circ}$, VI, do Código de Processo Civil, a técnica de distinção é relacionada à teoria dos precedentes, aonde há a adaptação do direito brasileiro.

Neste diálogo com o direito inglês, é interessante notar que a distinção como técnica de decisão jurídica, em certo sentido, não faz parte da teoria dos precedentes, pois diz respeito a toda e qualquer decisão jurídica, compondo o que no âmbito da teoria geral do direito é chamado de teoria da decisão jurídica (SCHUARTZ, 2005). O teor das regras de processo civil, inclusive, estabelece normas de decisão jurídica, algumas delas dirigidas ao juiz de 


\section{TÉCNICAS DE DISTINÇÃO NOS PRECEDENTES E RECURSOS REPETITIVOS: Democratização Processual e Tecnologias do Processo Civil Brasileiro}

direito e ao tribunal, como são os casos dos artigos 489 e 927 do Código de Processo Civil. Por se referirem também aos precedentes, portanto, pode-se entender que a teoria da decisão jurídica abarca a teoria dos precedentes.

Em função desta abrangência da teoria da decisão jurídica sobre os precedentes, é possível também classificar o distinguish tomando por base um sentido amplo e outro restrito. O sentido amplo equivale à "distinção-método"; e o sentido estrito, à "distinção-resultado". O sentido amplo de distinção corresponde à decisão jurídica; e o sentido estrito, à teoria dos precedentes.

Assim, é elucidada a confusão conceitual no tocante à utilização das duas técnicas jurídicas de distinção. Além disto, no campo da teoria do direito, nota-se que as duas técnicas são pertinentes tanto ao direito brasileiro como ao direito anglo-americano. Para Dierle Nunes e André Frederico Horta, "a distinção em sentido amplo consiste no processo argumentativo ou decisional por meio do qual o raciocínio por contra-analogias se manifesta" (2015, p. 311).

A citada contra-analogia é a contradita do que é análogo; ou seja, é o contraposto da analogia. A analogia e a contra-analogia integram a teoria do direito, não se confundindo com o precedente e a técnica de distinção no seu sentido estrito. No direito anglo-americano, tal diferenciação entre o precedente e a analogia é estudada por Frederick Schauer (2012) em termos de vinculação ao precedente, enquanto que na analogia há apenas persuasão racional. O uso obrigatório define os precedentes, o que não se aplica ao uso persuasivo da analogia.

Nesta perspectiva teórica, não há que se falar em graus de eficácia do precedente, ao contrário do que descrevem Chiassoni e MacCormick (ZANETI Jr., 2015), em diferentes classificações que podem envolver os precedentes persuasivos. Neste quadrante do precedente persuasivo, é possível conceber a analogia como sendo uma espécie de precedente, visto que o uso da analogia pode levar à persuasão, cujo grau médio ou forte tende à formação de um precedente em termos fáticos, aonde o distinguish se depreende por contra-analogia.

No prisma do direito positivo brasileiro, no entanto, há uma diferença marcante entre precedente e analogia. Conforme expressa o art. $4^{\circ}$ da Lei de Introdução às Normas do Direito Brasileiro, a analogia é fonte supletiva do direito brasileiro, só cabível na hipótese de omissão da lei. Os precedentes são fonte complementar do direito, em conformidade com a legislação processual civil brasileira. Assim, a diferenciação entre precedentes e analogia não está baseada no grau de eficácia, mas sim na função jurídica. A função da analogia é a de suprir a 
lei quando a mesma for omissa; e a função do precedente é a de complementar a interpretação da lei para conferir estabilidade, integridade e coerência ao direito, conforme prevê o art. 926, do Código de Processo Civil.

Entretanto, também é pertinente à analogia esta função jurisprudencial de manter o direito estável, íntegro e coerente. Sendo assim, quando for aplicada a técnica de distinção, seja ela para não seguir a analogia, seja para não seguir o precedente, deve-se atentar para que não haja o abuso processual. Na teoria dos precedentes, a condição impeditiva do abuso está ligada aos argumentos de distinção. A técnica de distinção, portanto, pressupõe a consistência na argumentação jurídica que pretende não seguir o precedente.

O requisito de consistência do direito alegado no caso concreto tem dois aspectos: o universal, concernente ao atendimento das normas válidas no direito; e outro particular, com respeito ao direito ajustado à realidade das provas produzidas no processo (ATIENZA, 2003). Embora o citado art. 926 nada explicite acerca da consistência do direito alegado, admite-se a interpretação jurídica sistemática, para efeitos da exigência legal de argumentos consistentes. É o que se depreende dos parágrafos $2^{\circ}$ e $3^{\circ}$, do art. 489, do Código de Processo Civil.

A legislação processual civil brasileira exige que a argumentação tenha o respaldo jurídico da consistência, tanto no referido aspecto universal, previsto no art. $489, \S 2^{\circ}$, quanto no seu aspecto particular, fixado no $\S 3^{\circ}$ do mesmo dispositivo legal. Neste último, o princípio da boa-fé se impõe sobre a decisão judicial, com consequências principiológicas ao que deve ser interpretado por boa conduta judicial no processo civil.

\section{A Boa-Fé Processual dos Argumentos aduzidos na Distinção}

Nesta acepção de boa-fé, tomando as lições de Judith Martins-Costa (2015) nas obrigações privadas, valida-se a boa-fé objetiva, no sentido de que há um padrão normativo de conduta processual fixado à atividade judicial. Em rol exemplificativo, sem esgotar o tema, reconhece-se que os princípios correlatos à boa-fé, isto é, aos deveres de boa condução do processo, são atrelados ao inteiro teor do art. 927, do Código de Processo Civil, que expressa: a segurança jurídica; a proteção da confiança; a isonomia; e a cooperação processual.

Segurança jurídica e proteção da confiança são princípios que, embora caminhem juntos, guardam uma autonomia funcional, sendo possível falar em segurança jurídica mesmo quando a confiança resta frustrada, pois há uma dimensão subjetiva na proteção da confiança.

Rev. de Processo, Jurisdição e Efetividade da Justiça | e-ISSN: 2525-9814 | Porto Alegre | v. 4 | n. 2 | p. $23-42$ | Jul/Dez. 2018 
Assim, a frustração pode acontecer independente da segurança jurídica, visto que a confiança é subjetiva e a proteção esperada pelo sujeito depende de uma base que pode ser alterada pela dinâmica de mudança do direito (ÁVILA, 2014).

Conforme verificado, a "base de confiança" é o requisito do princípio da proteção da confiança. A base tem que ser objetiva; e a confiança resultante daí é subjetiva. Por isto, é natural que tal base de confiança decorra, além da segurança jurídica, também do princípio da boa-fé. Afinal de contas, a boa-fé com respeito aos argumentos de identificação e de distinção do precedente é devida à crença de que o aplicador do direito tem lealdade à ordem jurídica, o que se ajusta à ideia da "boa crença" - em latim, bonna fides. O termo "confiança", inclusive, aparece no original alemão que traduz o princípio da boa-fé (MARTINS-COSTA, 2015).

O princípio da segurança jurídica também está implicado à boa-fé dos argumentos utilizados no processo, tendo em mente que a inteligibilidade do ordenamento jurídico garante a clareza, a consistência e a coerência jurídica, segundo aponta Humberto Ávila (2014). Com base nisto, há uma técnica especial de distinção, que permite compatibilizar, de um lado, a segurança jurídica e, do outro, a boa-fé do juízo que julga com argumentos de procedência à distinção. Trata-se da técnica da "distinção inconsistente", no common law reconhecida como procedimento de the drawing of inconsistent distinctions (MARINONI, 2013).

Nas palavras de Luiz Guilherme Marinoni, “embora a razão imediata da distinção inconsistente seja a não revogação (total) do precedente, a sua justificativa está nos valores da estabilidade, especialmente na segurança jurídica" (2013, p.332). Desta forma, evita-se revogar o precedente, mas se aplica uma distinção quanto às razões do respectivo precedente, para proceder a uma outra solução jurídica. A outra solução jurídica adotada está respaldada na segurança jurídica e na possibilidade de uma distinção inconsistente, mediante o confronto argumentativo com a boa-fé.

Quanto à isonomia dos julgados, a boa-fé está no enfrentamento dos argumentos, consoante determina o art. 489, $\S 1^{\circ}$, IV, do Código de Processo Civil, em face dos elementos de identificação e de distinção do precedente ou da questão de direito afetada no recurso repetitivo. O princípio da isonomia não garante apenas a igualdade, mas também o direito à diferença. Para que o direito à diferença aconteça, Bandeira de Mello leciona sobre as desequiparações permitidas no direito e Rosenfeld alude à discriminação lícita quando feita in 
bonam parte (CRUZ, 2005). Nota-se, assim, a interligação entre isonomia e boa-fé em sede de argumentação jurídica consistente e coerente.

Neste âmbito da boa-fé dos argumentos que visam às identificações e distinções sobre os precedentes, Maurício Ramires (2010) relata interessante método jurídico, oriundo de uma teoria matemática. $\mathrm{O}$ método consiste em se obter as respostas corretas fazendo para cada caso as perguntas corretas. Segundo Ramires, quando Tribe e Dorf analisaram o caso Bowers, perceberam que a grande divergência na decisão colegiada aconteceu porque cada julgador fez perguntas diferentes sobre o caso; por isto, obtiveram respostas diferentes. A partir disto, Tribe e Dorf trouxeram o método matemático de Lakatos para justificar como as distinções e identificações podem ser realizadas.

Tribe e Dorf partem de um exemplo mais simples para o entendimento da teoria de Lakatos (RAMIRES, 2010). O exemplo é o seguinte: suponha-se que seja comprovado que a soma dos ângulos de qualquer triângulo resulte em $180^{\circ}$ (regra); porém, na hipótese de um dos ângulos se situar sobre a superfície de uma esfera, de modo que cada um dos ângulos seja um ângulo reto, a sua soma total ultrapassa os $180^{\circ}$ (exceção). Este é o contraexemplo de uma regra. Para responder a um contraexemplo os matemáticos optam por duas abordagens típicas, segundo a crítica de Lakatos (RAMIRES, idem): a "exclusão do monstro" (monster-barring); e a "exclusão da exceção" (exception-barring). Ramires explica-as a seguir:

O monster-barrer vai sustentar que a palavra triângulo não inclui em seu significado o desenho de três ângulos retos na superfície de uma esfera e, portanto, não se trata de uma refutação, mas de uma monstruosidade. (...) o exception-barrer sabe que, para a grande maioria dos triângulos (que são desenhados em planos), a regra continua válida, razão pela qual ele não quer sacrificar o teorema por completo (RAMIRES, 2010, pp. 131-132).

O argumento jurídico da "exclusão do monstro" opera quando o intérprete nega o "caso-monstro" identificado com o precedente, o que condiz com uma outra técnica especial de distinção, conforme Ramires (2010, p. 132): a "distinção-sem-diferença" (distinction without a difference). Ainda que seja possível esta interpretação do precedente, o argumento jurídico baseado nesta abordagem da "exclusão do monstro" é fraco e pode ser refutado como medida de boa-fé. Se constatado tal argumento, a técnica da "distinção-sem-diferença" viola o princípio da isonomia, em decorrência da não identificação do caso com o precedente.

$\mathrm{Na}$ interpretação dos precedentes, a outra abordagem da "exclusão da exceção" se dá no ajustamento da proposição jurídica de uma regra. Nesta hipótese, a técnica de distinção pode gerar uma limitação do precedente e estabelecer uma nova ratio decidendi ou holding. A 
ratio é o coração do precedente; são as "razões de decidir" invocadas no processo. Nos termos do art. $489, \S 1^{\circ}, \mathrm{V}$, do Código de Processo Civil, a ratio do precedente está refletida nos “fundamentos determinantes" que justificam a decisão jurídica para seguir (identificação) ou para não seguir (distinção) a norma jurídica.

Nesta linha de raciocínio, só é possível aplicar as técnicas de distinção quando há a confrontação do caso com os fundamentos determinantes do precedente ou com a tese jurídica firmada sobre a questão de direito dos recursos repetitivos. Luiz Guilherme Marinoni formula a metódica desta técnica de distinção tomando por base o núcleo essencial do precedente, de modo a considerar que o "distinguishing exige, como antecedente lógico, a identificação da ratio decidendi do precedente" (2013, p. 325).

O juízo terá, então, que primeiro identificar a ratio do precedente, para depois julgar a distinção. O problema é que não há um critério definido para se chegar à ratio decidendi do precedente. Possivelmente, esta identificação da ratio do precedente seja "o ponto mais polêmico da teoria dos precedentes e de toda a teoria jurídica produzida no common law" (BUSTAMANTE, 2012, p. 259).

Justamente por tal aspecto controvertido, a boa-fé determina que o juízo atue com prudência na condução do processo, o que significa dizer, nos termos constitucionais do atual Estado Democrático de Direito, que a metódica do trabalho processual de identificação da ratio do precedente seja feita em conjunto com os demais sujeitos do processo. Saliente-se que a conduta de todos os sujeitos processuais está atrelada à boa-fé, não só por força de uma das normas fundamentais do processo civil estabelecer a conduta de boa-fé, como também em razão das hipóteses legais específicas que incidem sobre a boa-fé processual.

Dentre tais hipóteses legais, está a sanção processual aplicada às partes por motivo de violação da boa-fé no processo; isto é, por litigar de má-fé. Neste sentido, registre-se que a primeira hipótese legal de litigância de má-fé, prevista no art. 80, I, primeira parte, do Código de Processo Civil, apresenta uma incoerência que afronta a teoria dos precedentes e a teoria do direito contemporâneo.

Ao qualificar o litigante de má-fé naquele que deduz pretensão ou defesa contra texto expresso de lei, o referido dispositivo legal acompanha a fase do processualismo na teoria do processo, de acordo com a terminologia empregada por Daniel Mitidiero (2015). Ocorre que 
até mesmo o enunciado legal demanda um trabalho de interpretação jurídica, cujo escopo é o de compreensão, construção e, inclusive, reconstrução da norma.

Assim, a interpretação não resulta de um ato solitário de cognição judicial, mas sim de um trabalho processual conjunto (MITIDIERO, 2015). Por isto, quando é promovida uma pretensão ou uma defesa no sentido contrário ao texto que está expresso na lei, não há que se entender como aplicável a litigância de má-fé. Em tal contexto, o direito ao processo justo justifica a possibilidade jurídica de uma interpretação contra legem, a partir da argumentação racional do direito.

\section{A Face Democrática do Devido Processo de Distinção}

Em virtude destes aspectos normativos, assume-se a perspectiva de que o processo é o palco privilegiado para o desenvolvimento da interpretação e argumentação jurídica. Assim, uma vez que o processo possui este privilégio que lhe foi conferido no sistema jurídico, tal qual descrito na teoria procedimental-aberta da constituição (HABERLE, 1997), é inegável o seu caráter democrático relacionado à produção do direito.

Esta interrelação entre "processo e democracia" é uma das marcas ideológicas do que se conhece por "processo civil constitucionalizado". Em vista da interpretação integrativa do direito, o processo civil é amoldado ao Estado Constitucional Democrático. Com esta face, o novo processo civil não se atém tanto à teoria da ação, nem à teoria da jurisdição, uma vez que está voltado à organização de um procedimento participativo. Mauro Cappelletti (1999) registra tal perfil democrático, em nota sobre a interessante reflexão formulada por uma juíza federal norte-americana, conforme segue:

Enquanto, efetivamente, "a chave para abrir as portas de um tribunal" é,
simplesmente, "o pedido da parte", e enquanto as atividades do tribunal em grande
parte são "conduzidas publicamente", permanece "coberto de mistério", pelo
contrário, o modo pelo qual uma pessoa pode obter audiência "perante às câmaras
legislativas" ou "nos ofícios internos do poder executivo", mesmo quando, "o que
certamente ajuda, é muito rica e poderosa". Parece-me, portanto, que a produção
judiciária do direito, nada obstante todas as limitações que lhe são inerentes e das
quais já falei, não é em absoluto antidemocrática por si mesma (CAPPELLETTI,
1999, p. 106).

A crise da representatividade política, por sinal, é uma das causas desta mudança do espectro democrático ocupado pelo judiciário. A função do judiciário brasileiro, convergindo com a tradição anglo-americana, passou a ter exigências que antes cabiam apenas aos poderes 


\section{TÉCNICAS DE DISTINÇÃO NOS PRECEDENTES E RECURSOS REPETITIVOS: Democratização Processual e Tecnologias do Processo Civil Brasileiro}

políticos do executivo e do legislativo. Neste contexto funcional, não há politização da justiça, nem ativismo judicial, mas apenas o simples efeito de uma mudança institucional da política judiciária. Aliás, os referidos fenômenos políticos que impactam sobre o direito brasileiro são globais, como relatam Tate e Vallinder (1995).

É necessário, portanto, atribuir precisão terminológica para adequar o entendimento acerca dos diferentes fenômenos políticos desencadeados na história do judiciário brasileiro. Tais diferenciações são esclarecidas pelos juristas José Tesheiner e Rennan Thamay, tal como expõem: “A judicialização, no contexto brasileiro, é um fato, uma circunstância que decorre do modelo constitucional que se adotou, e não um exercício deliberado da vontade política" (2015, p. 275); e “o ativismo judicial é uma atitude, a escolha de um modo específico e proativo de interpretar a Constituição, expandindo o seu sentido e alcance” (2015, p. 275).

No caso da política judiciária sobre os precedentes e os recursos repetitivos, deve-se verificar que o judiciário somente está a receber os comandos normativos desta reorganização dos poderes políticos, cujo objetivo é o do aperfeiçoamento da gestão democrática da justiça. No tocante à teoria do direito, além disto, admite-se que, devido ao pressuposto de que há a diferença entre o texto e a norma; e, considerando que a interpretação do texto jurídico leva à produção normativa, resta afirmar que o processo civil é mais um instrumento legítimo de produção do direito.

Portanto, tratar a produção do direito pelo processo civil como democrática é superar o dogma racionalista de que o direito só pode provir da lei (SILVA, 2006). Observa-se, neste plano metodológico, a teoria realista que afirma que "a interpretação contra legem não existe" (TROPER, 2001, p. 71), pois não há como reduzir o direito à legalidade estrita e, nas ocasiões em que resultado do processo contraria a lei estrita, a fundamentação jurídica está alicerçada no direito. A interpretação da lei não poderia ser contrária a ela mesma quando se pressupõe que a interpretação jurídica tem como propósito a integração desta lei interpretada ao direito ou à ordem jurídica que a sustenta, renovando-a no seu entendimento normativo.

A interpretação jurídica da lei segue, assim, conforme ao direito vigente. Esta é uma das funções da prestação jurisdicional, prevista na lei processual civil: a de garantir que o direito seja estável, íntegro e coerente. Daí decorrem as necessidades sistemáticas de reforçar os pressupostos da colaboração no processo civil, baseados na não hierarquização da posição do juiz, na lógica dialogal e na boa-fé processual (MITIDIERO, 2015). Afinal, a interpretação 
jurídica não é tarefa exclusiva do indivíduo-juiz. O dever do juiz de oportunizar a participação dos atores na atividade jurisdicional legitima a ampla interpretação do direito no processo.

No princípio da cooperação processual, portanto, o juízo deverá se permitir enfrentar, dentro do procedimento do contraditório, todos os elementos de identificação e de distinção do precedente. $\mathrm{O}$ devido processo implicado nesta democratização do direito está manifesto na principiologia do processo justo. Este é o quadro organizacional democrático que sacra o direito fundamental ao processo justo, que abarca também os poderes executivo e legislativo, na linha das lições de Ingo Sarlet, Luiz Guilherme Marinoni e Daniel Mitidiero (2014).

Nota-se que o termo "justo" não tem a mesma conotação filosófica das teorias da justiça quando aplicado ao processo civil. Na realidade, o "justo processual” indica qual é o conteúdo jurídico mínimo do processo civil correto; ou seja, ao que é substancial e devido. Nesta acepção democrática, tal é a previsão constitucional de que "ninguém será privado da liberdade ou de seus bens sem o devido processo legal" (art. $\left.5^{\circ}, \mathrm{LIV}\right)$.

A primeira parte do referido preceito constitucional aponta para o processo penal. $\mathrm{Na}$ teoria processual penal, Rui Cunha Martins fala em “democraticidade” (2013, p. 73) como princípio unificador do direito, cujo modelo jurídico é democrático. Para o jurista português, o desafio teórico no processo penal é tornar o processo acusatório, desde que, por acusatório, atenda-se à qualificação constitucional-democrática. Esta qualidade democrática está ajustada ao princípio fundamental do processo justo.

No processo civil brasileiro, o direito ao processo justo encontra uma fundamentação teórica relevante na obra "Legitimação Democrática do Poder Judiciário no Novo CPC", de Gisele Mazzoni Welsch (2016). Nesta obra, a autora realiza um estudo sobre os precedentes e os recursos repetitivos, defendendo a participação das agências reguladoras e de outros órgãos técnicos, governamentais ou não, na posição de amicus curiae no processo civil. O objetivo é o de conferir legitimidade técnica e democrática aos precedentes e recursos repetitivos que refletem sobre as políticas públicas. Adota, portanto, o princípio democrático como norteador do direito ao processo justo.

Em relação à técnica processual de distinção, a obra alude às possibilidades jurídicas da "técnica do distinguishing de forma restritiva (restrictive distinguishing) ou de modo extensivo (ampliative distinguishing)" (WELSCH, 2016, p. 192). Destaca-se, ainda, a posição teórica de que o precedente não é aquele no qual a Corte julga pela primeira vez uma linha de raciocínio na decisão judicial: "somente o será se for seguida em futuros casos análogos" 
(WELSCH, 2016, p. 192). Se este é o momento de criação do precedente, pode-se afirmar que, por meio da técnica da distinção, é possível identificar o precedente. Pois, a identificação da ratio do precedente é o ponto de partida para aplicar a técnica da distinção.

Nas exigências da lei processual civil quanto à informação que deve ser prestada na rede mundial de computadores sobre o precedente e a questão de direito afetada no recurso repetitivo, a justificativa jurídica é de ordem democrática, por atender à transparência, que proporciona segurança jurídica, proteção da confiança, isonomia e boa-fé. Neste âmbito da democratização do processo civil, assim, a interpretação teleológica do uso da informática é mais apropriada, para que a tecnologia sirva à finalidade de mapeamento dos elementos que estejam presentes no precedente e no recurso repetitivo.

É correto trazer o argumento da eficiência da prestação jurisdicional no que concerne ao dito mapeamento dos elementos de identificação ou distinção do precedente e do recurso repetitivo, uma vez que esta é uma matéria favorável à identificação ou distinção do caso que poderá vir a ser vinculado ou afetado. Contudo, a programação computacional da rede de informática não pode ignorar o objetivo maior da transparência do direito judicial com base neste critério da eficiência administrativa. Diante do argumento da administração eficiente da justiça, privilegia-se o princípio democrático na efetividade do processo justo.

O plenário virtual das Cortes, por exemplo, ao viabilizar o contraditório no processo eletrônico, atende à função democrática compatível com a eficiência. No entanto, quando é levantado o argumento da técnica processual da distinção, o juízo que analisará a matéria não poderá considerar, unicamente, a busca no meio virtual por meio das palavras-chaves situadas na rede de computadores. Para a análise técnica da distinção do caso concreto, ainda que seja possível adicionar as informações acerca do precedente e do recurso repetitivo na plataforma computacional com algoritmos bastante precisos, espera-se que o tecnicismo da inteligência artificial não venha a substituir o humanismo do processo justo, o qual está sujeito ao jogo de tentativa e erro, conforme acontece nos processos democráticos.

\section{Procedimento de Distinção face ao Recurso Repetitivo}

O processo e a democracia estão, neste plano, correlacionadas à tecnologia. Contudo, por tecnologia não se deve entender apenas os recursos computacionais que estão à disposição 
das instituições jurídicas. É válido ir além desta noção estrita da tecnologia, para compreender também a dogmática jurídica como um recurso tecnológico eficiente na instrumentalização do processo justo. Decorre daí que os procedimentos técnicos do processo civil caminham junto com o processamento tecnológico, que não se reduz aos processos eletrônicos.

Podem sustentar tal fundamento, em conjunto, duas referências teóricas: uma, está na aludida proposta de Gisele Mazzoni Welsch (2016) sobre a participação dos atores sociais e órgãos técnicos que podem cooperar na condição de amicus curiae, em especial quando se tratar de processos repetitivos e de precedentes; e a outra referência teórica está na concepção de dogmática jurídica desenvolvida por Tercio Sampaio Ferraz Jr. (1998). De acordo com este último autor: "Ao envolver uma questão de decidibilidade, a Dogmática Jurídica manifesta-se como um pensamento tecnológico" (FERRAZ Jr., 1998, p. 90).

No sentido atribuído à relação entre direito e tecnologia, Tercio Sampaio Ferraz Jr. afirma que "as questões dogmáticas são tipicamente tecnológicas" (1998, p. 93) porque "têm uma função diretiva explícita" (1998, p. 93). Portanto, dois aspectos estão implicados nesta função diretiva do processo civil: um, é o aspecto diretivo da nova legislação processual civil, com normas que refletem a democratização estudada por Gisele Mazzoni Welsch (2016); e o outro aspecto diretivo, está na vinculação aos precedentes.

O processualista Georges Abboud (2016) contesta tal democratização do processo civil em matéria de vinculação aos precedentes. Segundo ele, os problemas apontados na nova legislação processual civil concernem ao momento processual da vinculação aos precedentes. $\mathrm{Na}$ análise comparativa com o common law, afirma-se que a dimensão de precedente atribuída à decisão da Corte de Precedentes é, consoante Georges Abboud, "sua aceitação pelas partes e pelas instâncias inferiores do Judiciário. Daí ele ser dotado de uma aura democrática que o precedente à brasileira não possui” (2016, p. 578). A crítica do autor está canalizada para a formação dos precedentes, cuja vinculação decorre, diretamente, da legislação processual civil e não de uma sólida experiência judiciária.

Entretanto, para usar a linguagem histórica de Reinhart Koselleck (2006), postula-se a compreensão deste "espaço de experiência" a partir do "horizonte de expectativas" que recai sobre os precedentes na legislação processual civil brasileira. Está claro que a justiça enfrenta um grave problema quanto à numerosidade dos processos. As expectativas relacionadas à vinculação dos precedentes brasileiros, inteiramente legítimas, buscam amenizar tal quadro de crise do judiciário, não só nos dados quantitativos, como também no que se refere à qualidade 


\section{TÉCNICAS DE DISTINÇÃO NOS PRECEDENTES E RECURSOS REPETITIVOS: Democratização Processual e Tecnologias do Processo Civil Brasileiro}

das decisões judiciais que objetivam uma maior proteção da confiança e isonomia prestada aos jurisdicionados.

Portanto, diante dos mecanismos processuais de identificação das soluções jurídicas comuns, é válido o argumento da eficiência processual. A eficiência de uma regra que está na ratio de um precedente ou no padrão decisório de casos judiciais repetitivos, como exemplo, está legitimada na proteção da confiança (SCHAUER, 2004). Na hipótese dos casos judiciais repetitivos, a técnica da distinção não gera a vinculação ao caso-piloto julgado pela Corte de Precedentes, mas vinculam o julgador à aplicação da técnica de confronto, de acordo com as palavras de Teresa Arruda Alvim Wambier e Bruno Dantas:

Vale dizer, ou acatam a orientação da corte superior, ou realizam analiticamente o
distinguishing. (...) Se, porém, no juízo de reenvio, o tribunal inferior realizar o
distinguishing, demonstrando analiticamente os pontos de fato ou de direito que
diferenciam o caso concreto da moldura delineada no recurso-piloto, e afirmando a
inaplicabilidade do comando normativo, deve-se concluir que há nova decisão,
impugnável por novo recurso, e não mais pelo que estava sobrestado (2016, p. 537).

Nesta seara dos recursos repetitivos, a técnica da distinção não funciona apenas como método de confronto com a ratio da questão afetada. A distinção também é um procedimento técnico que visa dar andamento ao processo que foi suspenso pela afetação da questão comum tocada no recurso repetitivo. O pleito pelo fim da suspensão do processo individual tem como fundamento a distinção quanto ao objeto da afetação.

É o que se depreende do $\S 9^{\circ}$, art. 1.037, do Código de Processo Civil, quanto aos recursos especial e extraordinário repetitivos, ao prover que: "Demonstrando distinção entre a questão a ser decidida no processo e aquela a ser julgada no recurso especial ou extraordinário afetado, a parte poderá requerer o prosseguimento do seu processo" (Lei no 13.105/2015). Em seguida, no mesmo art. 1.037, regulamenta-se, nesta ordem: primeiro, a autoridade competente que recebe o requerimento de distinção; segundo, a abertura do prazo de cinco dias para que a outra parte seja ouvida; terceiro, na hipótese de haver a procedência da distinção, estabelece-se o prosseguimento do processo por parte da autoridade competente ou, quando for o caso, a remessa ao tribunal superior de origem para que o processo prossiga; e, finalmente, dispõe-se sobre os recursos impetrados contra a decisão acerca da distinção, de acordo com o $\S 13$, cabendo o agravo de instrumento, quando o processo estiver no primeiro grau; e o agravo interno, se a decisão quanto ao requerimento de distinção for do relator (Lei $\left.\mathrm{n}^{\mathrm{o}} 13.105 / 2015\right)$.

Rev. de Processo, Jurisdição e Efetividade da Justiça | e-ISSN: 2525-9814 | Porto Alegre | v. 4 | n. 2 | p. $23-42$ | Jul/Dez. 2018 
Acontece que a técnica da distinção aplicável à decisão afetada nos casos repetitivos possui efeitos diferentes da técnica da distinção feita sobre o precedente. O interesse jurídico manifesto no requerimento de distinção sobre a decisão afetada nos casos repetitivos tem por objetivo a não-afetação à questão comum dos processos repetitivos, cujo efeito, na hipótese da procedência da distinção, consiste no fim do sobrestamento do processo afetado e suspenso. $\mathrm{O}$ requerimento de distinção sobre o precedente, de modo diverso, não é incidental no processo; o seu efeito imediato, na hipótese da procedência, é a não-vinculação do caso concreto com a ratio do precedente.

Aliás, o que caracteriza o "microssistema de julgamento de processos repetitivos" é "o sobrestamento dos processos pendentes que versam sobre a mesma controvérsia, na espera do julgamento da tese na causa/recurso modelo/piloto" (WOLKART, 2017, p. 376). Por isto, há dois desafios interpretativos sobre os elementos de identificação com a "tese jurídica" nos processos repetitivos, de acordo com Elaine Harzheim Macedo e Daniele Viafore: um, quanto à identificação da tese "que voltará em sede de incontáveis outros feitos a exigir tomada de posição pelo órgão julgador" (2015, p. 139); e dois, quanto à identificação das demandas "que efetivamente são da mesma natureza e espécie e aquelas que porventura possam guardar alguma peculiaridade" (2015, p. 139).

Em relação ao juízo de identificação da causa-piloto dos repetitivos, considera-se que “a lei divide a responsabilidade na seleção das causas-piloto entre o tribunal de origem e o tribunal superior que julgará o recurso repetitivo" (CABRAL, 2015, p. 1437)", como previsto no art. 1.036, §§ $1^{\circ}$ e $5^{\circ}$, do Código de Processo Civil. As técnicas da distinção são incidentes em qualquer grau da jurisdição, desde que o argumento jurídico seja validado na interpretação do precedente ou da causa-piloto do repetitivo no confronto com o caso-distinto. Desta forma, ter-se-á um novo caso pelas técnicas da distinção.

A democratização do processo civil, portanto, propicia a efetividade das técnicas da distinção. Ainda que a legislação processual civil imponha um forte grau de vinculação ao precedente formado no julgamento do caso repetitivo, as possibilidades argumentativas sobre as técnicas da distinção estão asseguradas no direito ao processo justo, por envolver a boa-fé e a cooperação processual.

\section{CONCLUSÃO}

Rev. de Processo, Jurisdição e Efetividade da Justiça | e-ISSN: 2525-9814 | Porto Alegre | v. 4 | n. 2 | p. $23-42$ | Jul/Dez. 2018 
Este artigo propôs analisar a interpretação das técnicas processuais da distinção, sob a ótica do Estado Democrático de Direito e da contemporaneidade. No bojo da interpretação democrática do processo civil, incidente sobre as técnicas da distinção, foram discutidos os princípios da boa-fé processual, da segurança jurídica, da proteção da confiança, da isonomia, da colaboração no processo civil, do contraditório, da transparência, da eficiência e do devido processo justo. Do ponto de vista da contemporaneidade, foram observadas as mudanças interpretativas sobre o processo civil e, junto desta questão jurídica, a aplicação da tecnologia que deve ser conformada à referida interpretação do processo civil.

Assim, os objetivos deste estudo são de duas ordens, uma introdutória e outra prática. Um objetivo é o de introduzir o debate da interpretação das técnicas da distinção no panorama contemporâneo da tecnologia e da democratização do processo civil. O outro objetivo é o de buscar elucidar algumas aplicações processuais das técnicas da distinção sobre os precedentes e os recursos repetitivos. Longe de pretender dar uma resposta definitiva sobre a interpretação das técnicas da distinção, portanto, tais objetivos específicos foram contemplados.

\section{REFERÊNCIAS}

ABBOUD, Georges. Processo Constitucional Brasileiro. São Paulo: Editora Revista dos Tribunais, 2016.

ATIENZA, Manuel. As Razões do Direito: teorias da argumentação jurídica; trad. Maria Cristina Guimarães Cupertino. $3^{\text {a }}$ ed. São Paulo: Landy, 2003.

ÁVILA, Humberto. Teoria da Segurança Jurídica. $3^{\mathrm{a}}$ ed. São Paulo: Malheiros Editores, 2014.

BUStamante, Thomas da Rosa. Teoria do Precedente Judicial: a justificação e a aplicação de regras jurisprudenciais. São Paulo: Noeses, 2012.

CABRAL, Antonio do Passo. Comentários ao Incidente de Resolução de Demandas Repetitivas / In. Comentários ao Novo Código de Processo Civil; coord. Antonio Passo Cabral, Ronaldo Cramer. Rio de Janeiro: Forense, 2015.

CAPPELLETTI, Mauro. Juízes Legisladores? - trad. Carlos Alberto Alvaro de Oliveira. Porto Alegre: Sergio Antonio Fabris Editor, 1999.

CRAMER, Ronaldo. Precedentes Judiciais: teoria e dinâmica. Rio de Janeiro: Forense, 2016. 
CRUZ, Álvaro Ricardo Souza. O Direito à Diferença: as ações afirmativas como mecanismo de inclusão social de mulheres, negros, homossexuais e pessoas portadoras de deficiência. $2^{\mathrm{a}}$ ed. Belo Horizonte: Del Rey, 2005.

DIDIER Jr., Fredie. Curso de Direito Processual Civil: teoria da prova, direito probatório, ações probatórias, decisão, precedente, coisa julgada e antecipação dos efeitos da tutela / Fredie Didier Jr., Paula Sarno Braga e Rafael Alexandria de Oliveira - 10 a ed. - Salvador: Ed. Jus Podivm, 2015.

FACCHINI NETO, Eugênio; e CORDEIRO, Karine da Silva. O Precedente Vinculante no Sistema Norte-Americano: quando reproduzir o passado é mais importante do que modificar o presente / In. Revista Magister de Direito Civil e Processual Civil; v. 13, n. 75, p. 81-121, nov./dez. Porto Alegre: Magister, 2016. Disponível em:

http://bdjur.stj.jus.br/jspui/handle/2011/107949 . Acesso: 24/ 07/2018.

FERRAZ Jr., Tercio Sampaio. Função Social da Dogmática Jurídica. São Paulo: Editora Max Limonad, 1998.

HERZOG, Benjamin. A Interpretação e a Aplicação do Direito na Alemanha e no Brasil: uma análise do ponto de vista da teoria de direito comparado funcional, da teoria de direito comparado pós-moderno e da teoria do legal transplants / In. Direito Privado, Constituição e Fronteiras: encontros da Associação Luso-Alemã de Juristas no Brasil; org. Stefan Grundmann... [et al.]. $2^{\text {a }}$ ed. São Paulo: Editora Revista dos Tribunais, 2014.

JOBIM, Marco Félix. Entendendo a Nomenclatura dos Precedentes / In. Diálogos Constitucionais de Direito Público e Privado; n. 2; org. Liane Tabarelli Zavascki, Marcia Andrea Bühring, Marco Félix Jobim. Porto Alegre: Livraria do Advogado Editora, 2013.

KOSELLECK, Reinhart. Futuro Passado: contribuição à semântica dos tempos históricos; trad. Wilma Patrícia Maas; e Carlos Almeida Pereira; rev. César Benjamin; $3^{\mathrm{a}}$ reimpressão. Rio de Janeiro: Contraponto: Ed. PUC-Rio, 2006.

MACEDO, Elaine Harzheim; e VIAFORE, Daniele. A Decisão Monocrática e a Numerosidade no Processo Civil Brasileiro. Porto Alegre: Livraria do Advogado Editora, 2015.

MARINONI, Luiz Guilherme. Precedentes Obrigatórios. $3^{\text {a }}$ ed. São Paulo: Editora Revista dos Tribunais, 2013.

MARTINS, Rui Cunha. O Ponto Cego do Direito: the brazilian lessons - $3^{\mathrm{a}}$ ed. - São Paulo: Editora Atlas, 2013.

MITIDIERO, Daniel. Colaboração no Processo Civil: pressupostos sociais, lógicos e éticos $-3^{\mathrm{a}}$ ed. - São Paulo: Editora Revista dos Tribunais, 2015. 


\section{TÉCNICAS DE DISTINÇÃO NOS PRECEDENTES E RECURSOS REPETITIVOS: Democratização Processual e Tecnologias do Processo Civil Brasileiro}

NUNES, Dierle; HORTA, André Frederico. Aplicação de Precedente e Distinguishing no CPC/2015: uma breve introdução / In. Precedentes; coord. Fredie Didier Jr. ... [et al.] Salvador: Juspodivm, 2015.

RAMIRES, Maurício. Crítica à Aplicação de Precedentes no Direito Brasileiro. Porto Alegre: Livraria do Advogado Editora, 2010.

SARLET, Ingo Wolfgang. Curso de Direito Constitucional / Ingo Wolfgang Sarlet, Luiz Guilherme Marinoni, Daniel Mitidiero - $3^{\mathrm{a}}$ ed. - São Paulo: Editora Revista dos Tribunais, 2014.

SCHAUER, Frederick. Las Reglas em Juego: un examen filosófico de la toma de decisiones basada en reglas en el derecho y en la vida cotidiana; trad. Claudina Orunesu, Jorge L. Rodríguez. Madrid, Barcelona: Marcial Pons, 2004.

Thinking Like a Lawyer: a new introduction to legal reasoning. Cambridge, Massachusetts: Harvard University Press, 2012.

SCHUARTZ, Luís Fernando. Norma, Contingência e Racionalidade: estudos preparatórios para uma teoria da decisão jurídica. Rio de Janeiro: Renovar, 2005.

TATE, C. Neal; e VALLINDER, Torbjörn. The Global Expansion of Judicial Power. New York: New York University Press, 1995.

TESHEINER, José Maria Rosa. Teoria Geral do Processo: em conformidade com o novo CPC / José Maria Rosa Tesheiner, Rennan Faria Krüger Thamay. Rio de Janeiro: Forense, 2015.

TROPER, Michel. La Théorie du Droit, Le Droit, L'État. Paris: Presses Universitaires de France, 2001.

WAMBIER, Teresa Arruda Alvim. Recurso Especial, Recurso Extraordinário e a Nova Função dos Tribunais Superiores no Direito Brasileiro: (de acordo com o CPC/2015 e a Lei 13.256/16) / Teresa Arruda Alvim Wambier, Bruno Dantas - $3^{\mathrm{a}}$ ed. - São Paulo: Editora Revista dos Tribunais, 2016.

WELSCH, Gisele Mazzoni. Legitimação Democrática do Poder Judiciário no Novo Código de Processo Civil. São Paulo: Editora Revista dos Tribunais, 2016 (coleção Liebman; coord. Teresa Arruda Alvim Wambier, Eduardo Talamini).

WOLKART, Erik Navarro. O fetiche dos microssistemas no novo Código de Processo Civil: integrações normativas entre procedimentos para formação de precedentes e para julgamentos de processos repetitivos / In. A Nova Aplicação da Jurisprudência e Precedentes no CPC/2015; coord. Dierle Nunes, Aloisio Mendes, Fernando Jayme. São Paulo: Editora Revista dos Tribunais, 2017.

Rev. de Processo, Jurisdição e Efetividade da Justiça | e-ISSN: 2525-9814 | Porto Alegre | v. 4 | n. 2 | p. $23-42$ | Jul/Dez. 2018 
ZANETI Jr., Hermes. O Valor Vinculante dos Precedentes: o modelo garantista e a redução da discricionariedade judicial - uma teoria dos precedentes normativos formalmente vinculantes. Salvador: Editora Juspodivm, 2015. 